\title{
Epithelioid \\ hemangioendothelioma of the liver: A report of two cases
}

\author{
JE Morris, MD, DA MAlatjalian, MD, A BODURTHRA, MD, M SMITH, MD, O Koller, MD, \\ J BHAN, MD, L MAGTIBAY, MD
}

JE MORRIS, DA MAlatjallan, A Bodurthra, et al. Epithelioid hemangioendothelioma of the liver: A report of two cases. Can J Gastroenterol 1993; 7 (7):530-534. Epithelioid hemangioendothelioma (EHE) is an uncommon tumour of endothelial origin having borderline malignant potential which frequently is initially misdiagnosed when occurring in the liver, often as cholangiocarcinoma, metastatic carcinoma or veno-occlusive disease. The authors report two cases of hepatic EHE. The first case presented in a 33-year-old female and was originally misdiagnosed as cholangiocarcinoma. Only after re-evaluation of the case seven years later, because of an unexpectedly indolent clinical course, was the correct diagnosis made. The second case presented in a 26-year-old female having nonspecific gastrointestinal complaints. The diagnosis of hepatic EHE was made from a wedge biopsy of liver taken during an exploratory laparotomy. In both cases, immunohistochemical reactivity of the tumour cells for von Willebrand factor (FVIIIR:Ag) and Ulex europeaus I lectin was key to the final diagnosis. The first patient, to this time, remains asymptomatic. The second patient underwent liver transplantation and is being followed (now one year since the initial diagnosis). Hepatic EHE can present a diagnostic dilemma. The use of immunohistochemical techniques to demonstrate the vascular origin of this tumour is essential for its diagnosis. Better awareness of this lesion and the features differentiating it from other histologically similar lesions will prevent exposing affected patients to unnecessary investigations and treatments.

Key Words: Differential diagnosis, Epithelioid hemangioendothelioma, Primary liver tumour, Tumour markers

\section{Hémangio-endothéliome épithélioïde du foie: deux rapports de cas}

RÉSUMÉ: L'hémangio-endothéliome épithélioïde est une tumeur rare d'origine endothéliale, dotée d'un potentiel de malignité limite et qui est souvent mal diagnostiquée au début lorsqu'elle survient dans le foie, souvent prise à tort pour un cholangiocarcinome, un carcinome métastatique ou une maladie véno-occlu-

Departments of Pathology, Surgery and Medicine, Victoria General Hospital and Dalhousie University, Halifax, Nova Scotia; and Regional Laboratories and Department of Medicine,

Dr Everett Chalmers Hospital, Fredericton, New Brunswick

Correspondence and reprints: Dr John Morris, Department of Pathology, Victoria General Hospital, Halifax, Nova Scotia B3H 2 Y9

Received for publication November 20, 1992. Accepted March 25, 1993
E PITHELIOID HEMANGIOENDOTHELIoma (EHE) is an uncommon tumour of endothelial cell origin which has been reported to occur as a primary lesion in soft tissues, bone, lungs and liver $(1,2)$. Primary hepatic EHE appears to be rare, based on the number of cases reported in the medical literature. However, because of the diagnostic difficulties it can present - as has been demonstrated by the frequency of initial misdiagnosis - it may be a more common tumour than reported (2-12). The etiology is uncertain. However, predisposing risk factors for other primary hepatic malignancies have been postulated $(13,14)$. The clinical course of hepatic EHE is variable and unpredictable, and consensus regarding treatment has yet to be established $(2,3,5$, 7). However, for selected patients, liver transplantation is more frequently becoming a treatment option $(4,5)$. The authors report two cases of hepatic EHE and briefly review the available literature.

\section{CASE PRESENTATIONS}

Case 1: A 33-year-old female with an unremarkable past medical history, presented with an epigastric mass and recent $6 \mathrm{~kg}$ weight loss. She was admitted to hospital for investigation. Laboratory data on admission were: hemoglobin, $142 \mathrm{~g} / \mathrm{L}$; white blood cell count, 
sive. Les auteurs font état de deux cas d'hémangio-endothéliome épithélioïde du foie: le premier concerne une patiente de 33 ans chez qui l'on avait à erronément posé initialement un diagnostic de cholangiocarcinome. Ce n'est qu'après une réévaluation de son cas, sept ans plus tard, à cause d'une évolution clinique inhabituellement lente, que le diagnostic juste a été posé. Le deuxième cas s'est présenté chez une patiente de 26 ans qui se plaignait de symptômes gastro-intestinaux non spécifiques. Le diagnostic d'hémangio-endothéliome épithélioïde hépatique a été posé à partir d'une biopsie du foie, prélevée lors d'une laparotomie exploratoire. Dans les deux cas, la réactivité immuno-histo-chimique des cellules tumorales à l'égard du facteur de von Willebrand et de la lectine Ulex Europeaus I a été la clé du diagnostic final. La première patiente, à l'heure actuelle, demeure asymptomatique; la seconde a subi une transplantation hépatique et est suivie (un an s'est écoulé depuis le diagnostic initial). L'hémangio-endothéliome épithélioïde peut représenter un dilemme diagnostique. Le recours à des techniques immuno-histo-chimiques afin de démontrer l'origine vasculaire de cette tumeur est essentiel pour son diagnostic. Une meilleure connaissance de cette lésion et de ses caractéristiques différentielles par rapport à d'autres lésions histologiquement similaires, empêchera les patients affectés d'être soumis à des investigations ou des traitements superflus.

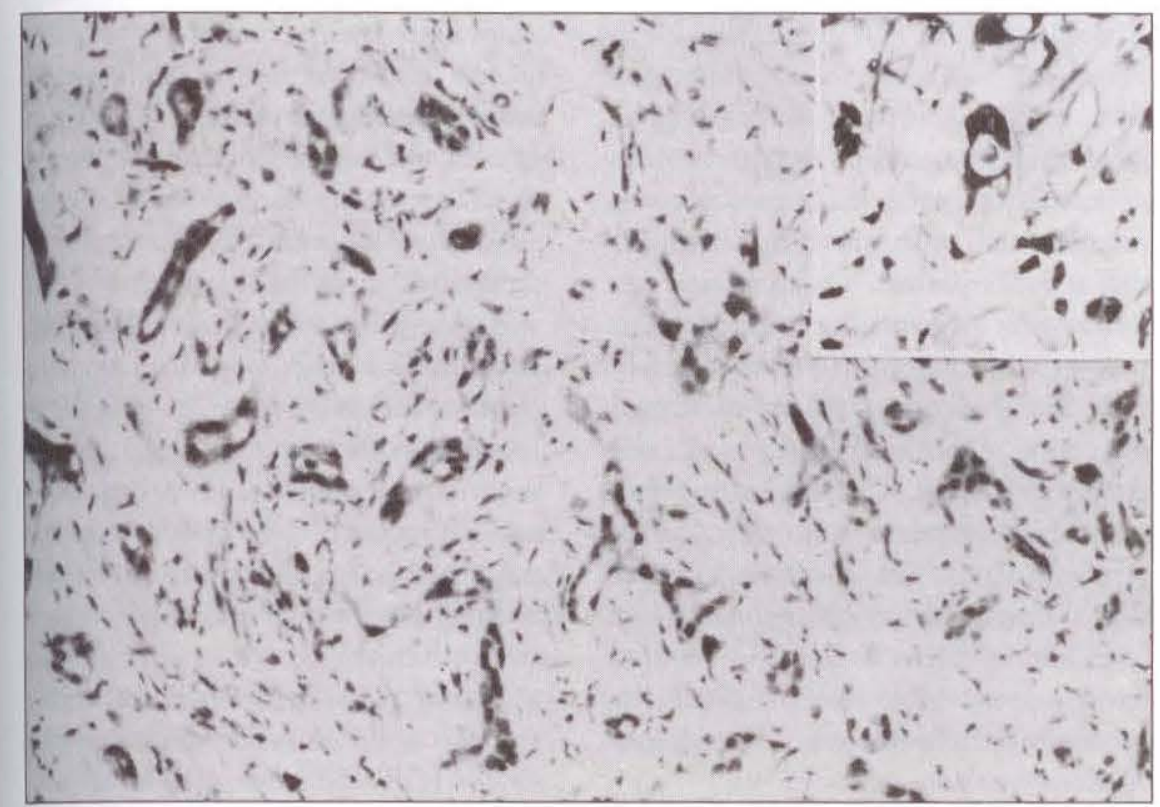

Figure 1) Strands and nests of tumour cells within a dense fibrotic stroma. Tumour cells with cytoplasmic vacuoles, one with a red blood cell (inset)

$7.8 \times 10^{9} / \mathrm{L}$; erythrocyte sedimentation rate, $22 \mathrm{~mm} / \mathrm{h}$; total protein, $77 \mathrm{~g} / \mathrm{L}$; albumin, $42 \mathrm{~g} / \mathrm{L}$; total bilirubin, $29 \mu \mathrm{mol} / \mathrm{L}$, alanine aminotransferase, $76 \mathrm{U} / \mathrm{L}$; aspartate aminotransferase, $147 \mathrm{U} / \mathrm{L}$; and alkaline phosphatase, $984 \mathrm{U} / \mathrm{L}$.

An abdominal ultrasound revealed a large, solid, echogenic mass replacing much of the left lobe of the liver. When the patient underwent a laparotomy a wedge biopsy of the left lobe of liver was taken. The biopsy specimen showed two nodular, solid, grey-white lesions, the larger measuring $2 \mathrm{~cm}$ in the greatest dimension. Histologically, the lesions showed proliferation of predominantly epithelioid cells which had abundant eosinophilic cytoplasm, large nuclei with coarse chromatin and prominent nucleoli. There were fewer spindle-shaped cells having similar nuclear features. Many of the cells showed large intracytoplasmic vacuoles of various sizes and, in areas, neoplastic cells were arranged in a single layer forming a structure with a central lumen. In some of these lumina were red blood cells. Mitotic figures were infrequent. The neoplastic cells were dispersed within a rather dense fibrotic stroma. At the periphery of the tumour foci, tumour cell involvement of adjacent sinusoids was seen with compression and mild disruption of the hepatocytic plates. Invasion of hepatic veins was prominent. These lesions were histologically diagnosed as poorly differentiated cholangiocarcinoma (Figure 1). Further workup for metastases was negative.

Treatment was initiated with doxorubicin, 5-fluorouricil (5-FU) and vincristine. Multiple courses were given and after four years, repeated diagnostic imaging showed the tumour had apparently regressed. However, during this time, the patient had developed doxorubicin cardiotoxicity (cardiomyopathy) and vincristine neurotoxicity requiring discontinuation of these drugs. 5-FU was continued as a single agent for a short course afterward. The chemotherapy was stopped and not restarted for two years (when an asymptomatic lung lesion was identified radiographically). Although a tissue diagnosis of this lesion was not obtained, 5-FU was restarted for a presumed metastasis. The chemotherapy was discontinued after two courses according to the patient's wishes. Further progression of the lung and hepatic lesions was not noted and the patient remained free from further problems.

Because of the unexpectantly long, indolent clinical course, the original diagnosis of cholangiocareinoma made seven years earlier was reviewed. The neoplastic cells exhibited reactivity for the endothelial cell markers von Willebrand factor antigen (vWF:Ag) and Ulex europeaus I lectin (Figure 1). Positive staining was seen within the cytoplasm, intracytoplasmic vacuoles and vascular lumina as granular or homogeneous deposits. Approximately $50 \%$ of the neoplastic cells were reactive for each marker. The histological features were reinterpreted and a revised diag. nosis of hepatic EHE was made. To this time, now 10 years since first presenting to her physician, the patient remains asymptomatic. 


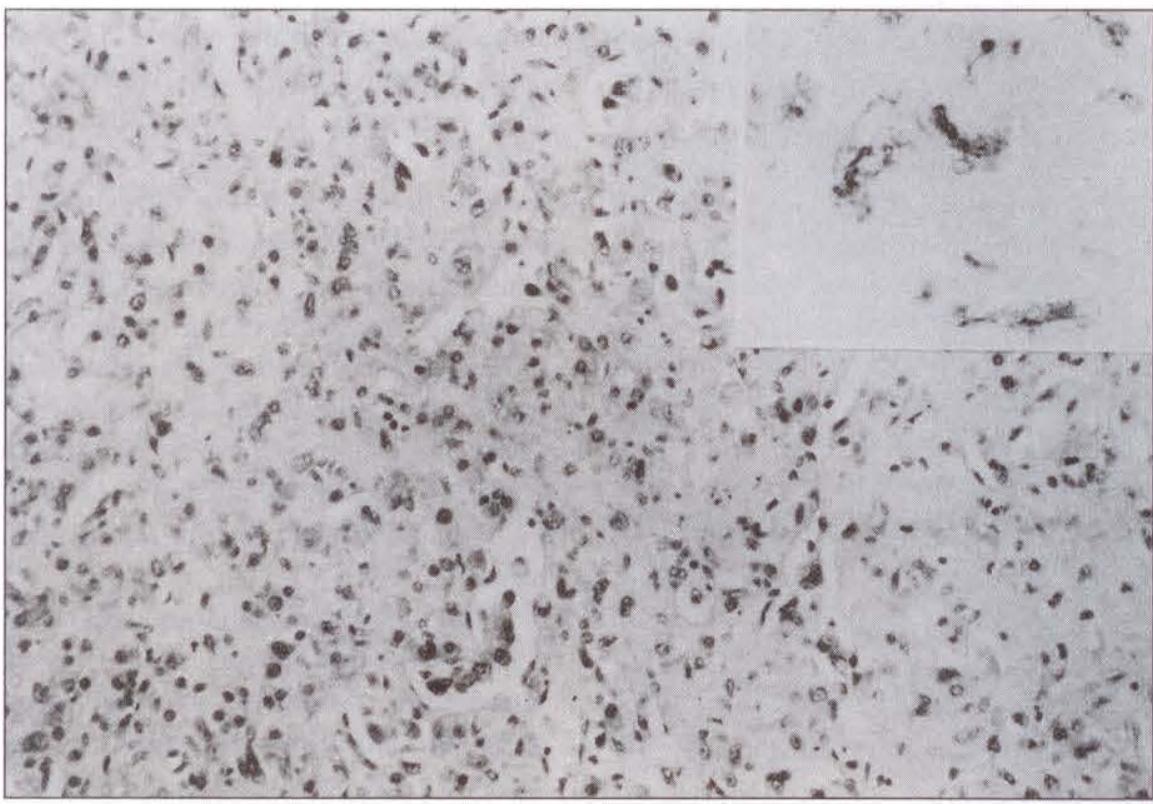

Figure 2) Tumour cells dispersed within fibrotic stroma, many with cytoplasmic vacuoles and occasional papillae formation. Individual tumour cells with positive staining of cytoplasmic vacuoles for van Willebrand factor (inset)

Case 2: A 26-year-old female presented with a four-month history of dull, intermittent, right upper quadrant abdominal pain, nausea and $15 \mathrm{~kg}$ weight loss. She was admitted to hospital for investigation. There had been prior abuse of alcohol, and prescription and illegal drugs. She had been taking oral contraceptives for 10 years. Laboratory data on admission were: hemoglobin, 127 $\mathrm{g} / \mathrm{L}$; white blood cell count, $7 \times 10^{9} / \mathrm{L}$, albumin, $38 \mathrm{~g} / \mathrm{dL}$; alkaline phosphatase, $435 \mathrm{U} / \mathrm{L}$; lactate dehydrogenase, 138 $\mathrm{U} / \mathrm{L}$; total bilirubin, $6 \mu \mathrm{mol} / \mathrm{L}$; aspartate aminotransferase, $29 \mathrm{U} / \mathrm{L}$; glutamyltransferase, $138 \mathrm{U} / \mathrm{L}$; glucose, $5.1 \mathrm{mmol} /$ $\mathrm{L}$; and amylase, $50 \mathrm{U} / \mathrm{L}$. Alpha-fetoprotein and carcinoembryonic antigen (CEA) were not elevated. Antinuclear antigen was negative as were hepatitis B surface antigen and anti-hepatitis B core antigen. An abdominal ultrasound showed multiple hypoechoic masses of varying sizes within both lobes of the liver. Further investigations for extrahepatic lesions were negative.

The patient underwent an exploratory laparotomy during which a wedge biopsy of liver was taken. The biopsy showed several grey-white, solid masses (the largest measured $2 \mathrm{~cm}$ in greatest dimension). Histologically (Figure 2), the lesions showed features similar to those in case 1 except that most cells vascular and intrasinsoidal invasion and/or embolization and a mixed inflammatory infiltrate, including foreign body-type granulomas. Approximately $60 \%$ of the neoplastic cells exhibited reactivity of both vWF:Ag and Ulex europeaus I lectin. The diagnosis of hepatic EHE was made.

The patient underwent successful liver transplantation one year ago and currently is being followed. At this time, now two years since first presenting, there is no evidence of extrahepatic dissemination.

\section{DISCUSSION}

EHE is an uncommon tumour of endothelial cell origin. Weiss and Enzinger (1) suggested the name after studying the soft tissue counterpart of the lesion, the intravascular bronchiolalveolar tumour originally described in the lung which was later shown to have a vascular histogenesis (1). Based on the epithelioid-appearing tumour cells, a pattern of solid growth and a clinical course intermediate between hemangioma and angiosarcoma, they suggested the new name, EHE. Other names have been proposed including sclerosing endothelial tumour, scleroswere singly dispersed. There was intra- ing angiogenic tumour and sclerosing epithelioid angiosarcoma (2).

Fewer than 100 case of primary hepatic EHEs have been reported in the medical literature (2-14). The patients ranged in age from 12 to 86 years (mean 41.5 ) with a female:male ratio of $2: 1$. The most frequent signs and symptoms at presentation included right upper quadrant pain or discomfort, hepatomegaly, jaundice, fever, anorexia, weight loss and ascites. Laboratory data at presentation were rather nonspecific, but alkaline phosphatase was frequently elevated. Alpha-fetoprotein and CEA levels were normal. Most lesions were multiple and ranged in size from 0.5 to $12 \mathrm{~cm}$. Approximately $40 \%$ of patients had, at some point, mediastatic extrahepatic tumour. The most common sites of metastases were lung, abdominal lymph nodes, peritoneum, spleen and mediastinum. Survival was extremely variable, ranging from months to 28 years from initial diagnosis. However, in many patients the tumour showed unusually slow progression, a feature of this lesion.

To diagnose an hepatic EHE can be difficult. The clinical features are nonspecific and laboratory investigations are most useful in identifying general hepatic injury and in aiding the exclusion of some other lesions. Radiographically, the entity can present as nodular or diffuse lesions, the diffuse form probably resulting from coalescence of multiple nodules and representing a more advanced form of disease $(7,8)$. The radiographic appearance of nodular hepatic EHE is similar to that of some hepatic metastases, making differentiation difficult. However, certain combined radiological findings have been suggested as being useful in the identification of the diffuse form; these are moderately increased tumour vascularity spreading predominantly along the outside edge of both hepatic lobes, hypovascular areas within the tumour, intratumoural calcification, enlargement of the uninvolved hepatic parenchyma with resulting deformity of hepatic contour and absence of some intrahepatic portal branches shown angiographically (7). 
Histologically, the neoplasm has features which can present diagnostic difficulty. The neoplastic cells have dendritic or epithelioid appearance and are seen infiltrating sinusoids and veins, dispersed within a variable but often abundant stroma that may have myxoid, sclerotic or calcifying features. Microscopic evidence of vascular differentiation may be seen in the form of variably sized intracytoplasmic vacuoles and in well-defined structures lined by neoplastic cells and containing red blood cells within central lumina $(4,10)$. The presence of dendritic cells signifying mesenchymal origin, the involvement of branches of hepatic and portal veins and the infiltrative nature of growth (but with peripheral preservation of hepatic acinar structure) help to differentiate hepatic EHE from cholangiocarcinoma and hepatocellular carcinoma. Negative staining for mucin and bile, negative immunochemical staining for CEA and alpha-fetoprotein and the presence of many thin filaments and Weibel-Palade bodies, ultrastructurally, are other useful differentiating features $(2,10)$. However, for practical purposes, it is the identification of the tumour cells' vascular origin, based on their immunohistochemical reactivity for $\mathrm{vWF}: \mathrm{Ag}$ and Ulex europeaus I lectin, that is key to the correct diagnosis (2-12). Positive staining of the neoplastic cells tends to be variable and may be seen within the cytoplasm, intracytoplasmic vacuoles and/or within vascular lumina. Generally, the epithelioid cells stain for these

\section{REFERENCES}

1. Weiss SA, Enzinger FM. Epithelioid hemangioendothelioma: $A$ vascular tumour often mistaken for a carcinoma. Cancer 1982;50:970-81.

2. Ishak KG, Sesterhenn IA, Goodman MZD. Epithelioid hemangioendothelioma of the liver: A clinocopathologic and follow-up study of 32 cases. Hum Pathol 1984:15:839-52.

3. Ruben T, Bruguera M, Campo E, et al. Epithelioid hemangioendothelioma of the liver: Report of two cases. Liver 1988;8:105-10.

4. Scoazec JY, Lamy P, Degott C, et al. Epithelioid hemangioendothelioma of the liver: Diagnostic features and role endothelial markers more frequently and intensely than dendritic tumour cells, Furthermore, as the stromal component becomes more prominent, the number of positive cells and intensity of the staining reactions becomes less (12).

More recently, a new monoclonal antibody to endothelium (QBEND/10) has been reported to be superior to vWF:Ag and Ulex europeaus I lectin in identifying the characteristic intracytoplasmic lumina in EHE. It was found to be more sensitive than vWF:Ag and specific than Ulex europeaus I lectin for endothelium. Furthermore, QBEND/10 tended to stain the background stroma less than the other two markers, thereby allowing better visualization of cytoplasmic vacuoles and lumina (15).

Hepatic EHE may histologically resemble other vascular tumours, such as angiosarcoma. Criteria that are useful in the differentiation and point towards angiosarcoma include variable growth along hepatic plates, the presence of an interanastomizing pattern on reticular stains, anaplastic cytological features and the presence of mitotic figures (5). Hepatic EHE has also been confused for post necrotic fibrosis and veno-occlusive disease since, in certain cases, the histological appearance can make even the recognition of a neoplastic process being present difficult (11). It is the identification of dendritic and/or epithelioid cells positive for endothelial cell markers and which have an invasive growth pattern which points towards a neoplastic lesion of vascular

of liver transplantation.

Gastroenterology 1989;94:1447-53.

5. Ignazio RM, Satoru T, Andreas G, et al. Treatment of hepatic epithelioid hemangioendothelioma with liver transplantation. Cancer 1988;62:2079-84.

6. Fukayama M, Nihei Z, Takizawa T, et al. Malignant epithelioid hemangioendothelioma of the liver, spreading through the hepatic veins. Virchows Arch 1984:404:275-87.

7. Furui S, Itai Y, Ohtomo K, et al. Hepatic epithelioid hemangioendothelioma: Report of five cases. Radiology 1989:171:63-8.

8. Radin DR, Craig JR, Colletti PM, et al. Hepatic epithelioid hemangio- origin (ie, EHE), even if cellular atypia is relatively mild.

In our first case, the tumour was initially misdiagnosed as cholangiocarcinoma. Only later, after an unexpectedly indolent clinical course, was there reevaluation of the lesion and the correct diagnosis made. The histological evidence of vascular differentiation was originally misinterpreted. It was not until the tumour cells were identified as being of endothelial cell origin, based on reactivity for $\mathrm{vWF}: \mathrm{Ag}$ and Ulex europeaus I lectin, was the correct diagnosis made. Likewise, recognition of the derivation of neoplastic cells in the second case using immunohistochemical techniques, in conjunction with the clinical, radiological and other histological findings, was required to establish the correct diagnosis.

Although in our cases wedge biopsies were obtained for pathological diagnosis, needle biopsy may be adequate for diagnosis, providing the tumour has been adequately sampled and immunohistochemical techniques for identification of its vascular origin are used. At least one diagnosis of an hepatic EHE based on fine-needle aspiration cytology has been reported (16).

In conclusion, we hope to draw further awareness to this lesion and the diagnostic difficulties it can present. Misdiagnosis of this lesion can lead to unnecessary investigations and treatments. The use of immunohistochemical techniques for the identification of endothelial cell derivation often is essential for the correct diagnosis of EHE.

endothelioma. Radiology 1988;169:145-8.

9. Cobden I, Johri S, Terry G, et al. Hepatic epithelioid hemangioendothelioma: Difficult name, difficult diagnosis? Post Med J 1988;64:128-31.

10. Scoazec JV, Degott C, Reynes M, et al. Epithelioid hemangioendothelioma of the liver: An ultrastructural study. Hum Pathol 1989;20:673-81.

11. Eckstein RP, Ravich RB. Epithelioid hemangioendotheliorna of the liver. Report of two cases histologically mimicking veno-occlusive disease. Pathology 1986;18:459-62.

12. Dietze O, Davies SE. Williams R, Portmann B. Malignant epithelioid haemangioendothelioma of the liver: A clinicopathological and 
histochemical study of 12 cases.

Histopathology 1989;15:225-37.

13. Dean PJ, Haggitt RC, O'Hara CJ. Malignant epithelioid hemangioendothelioma of the liver in young women: Relationship to oral contraceptive use. Am J Surg Pathol 1985;9:695-704.

14. Gelin M, Van de Stadt J, Rickaert F, et al. Epithelioid hemangioendothelioma of the liver following contact with vinyl chloride. Recurrence after orthopic liver transplantation. J Hepatol 1989:8:99-106

15. Ramani P, Bradley NJ, Fletcher CD. QBEND/10, a new monocional antibody to endothelium: Assessment of its diagnostic utility in paraffin sections. Histopathology 1990;17:237-42.

16. Gambacorta M, Bonacina E. Epithelioid hemangioendothelioma: Report of a case diagnosed by fine-needle aspiration. Diagn Cytopathol 1989;5:207-10. 


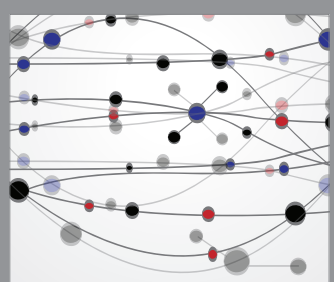

The Scientific World Journal
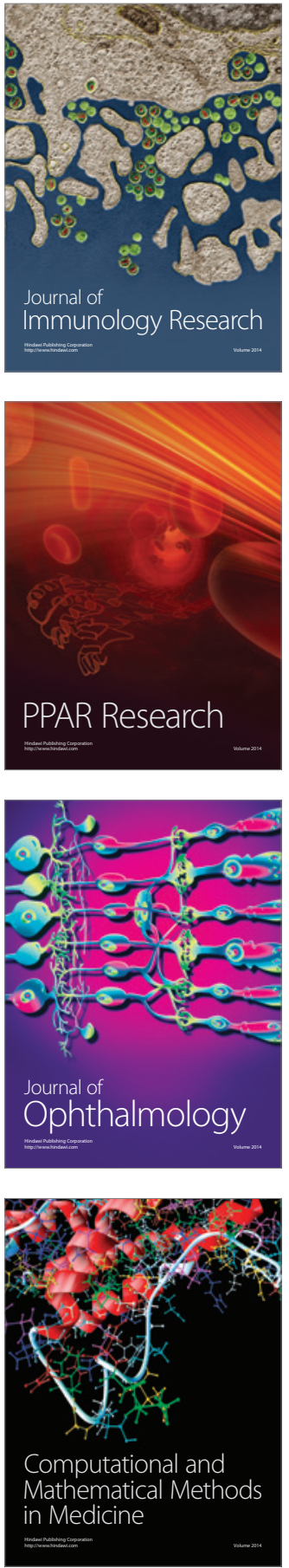

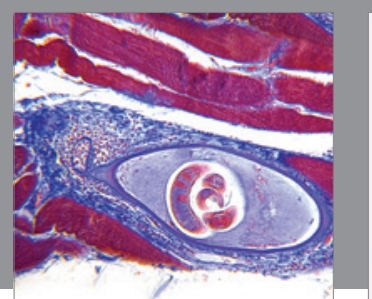

Gastroenterology Research and Practice

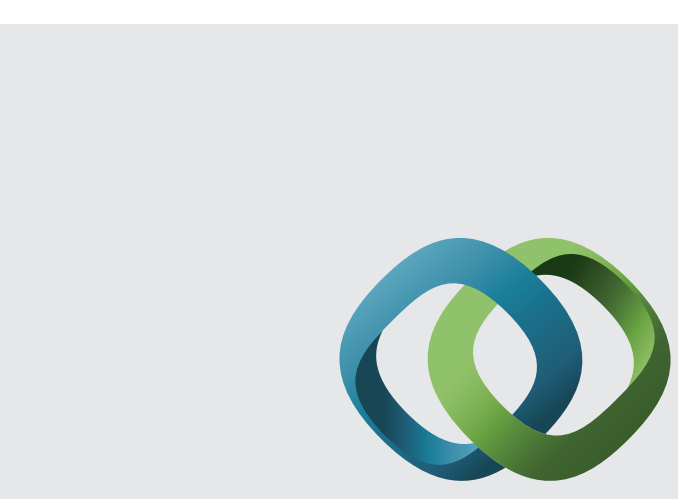

\section{Hindawi}

Submit your manuscripts at

http://www.hindawi.com
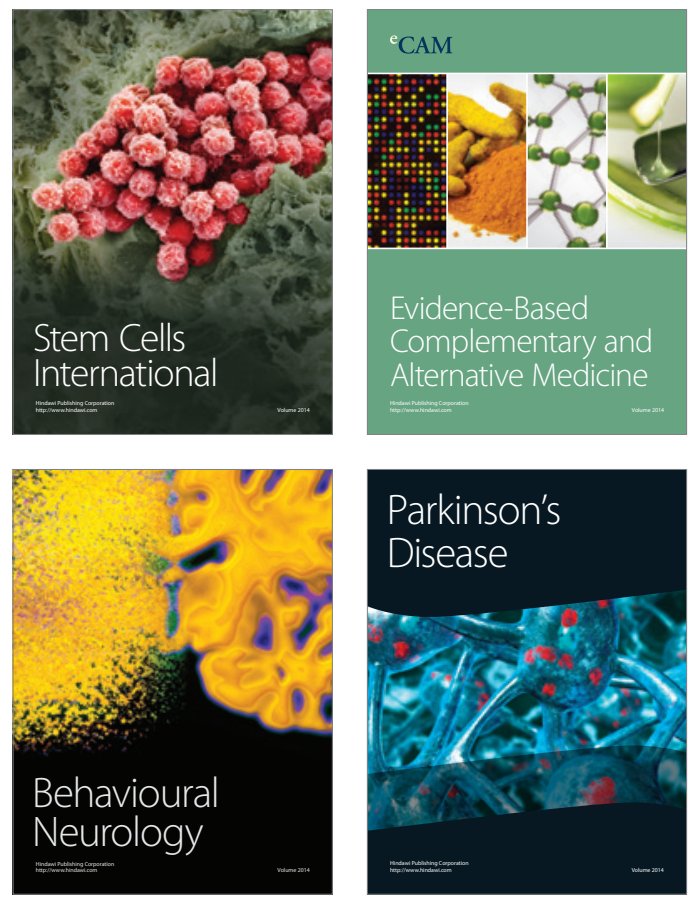
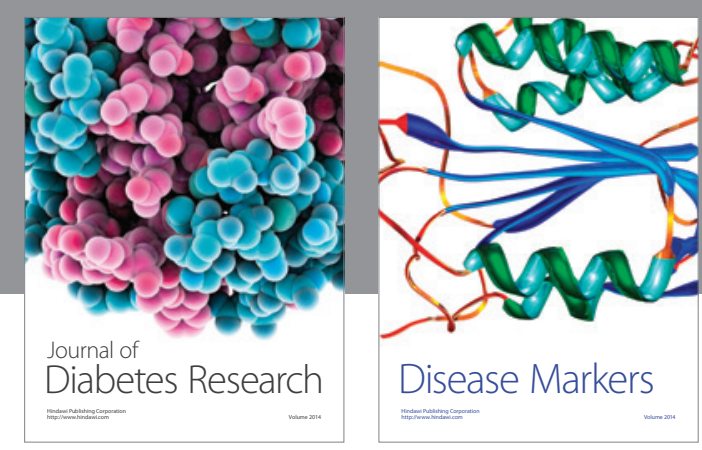

Disease Markers
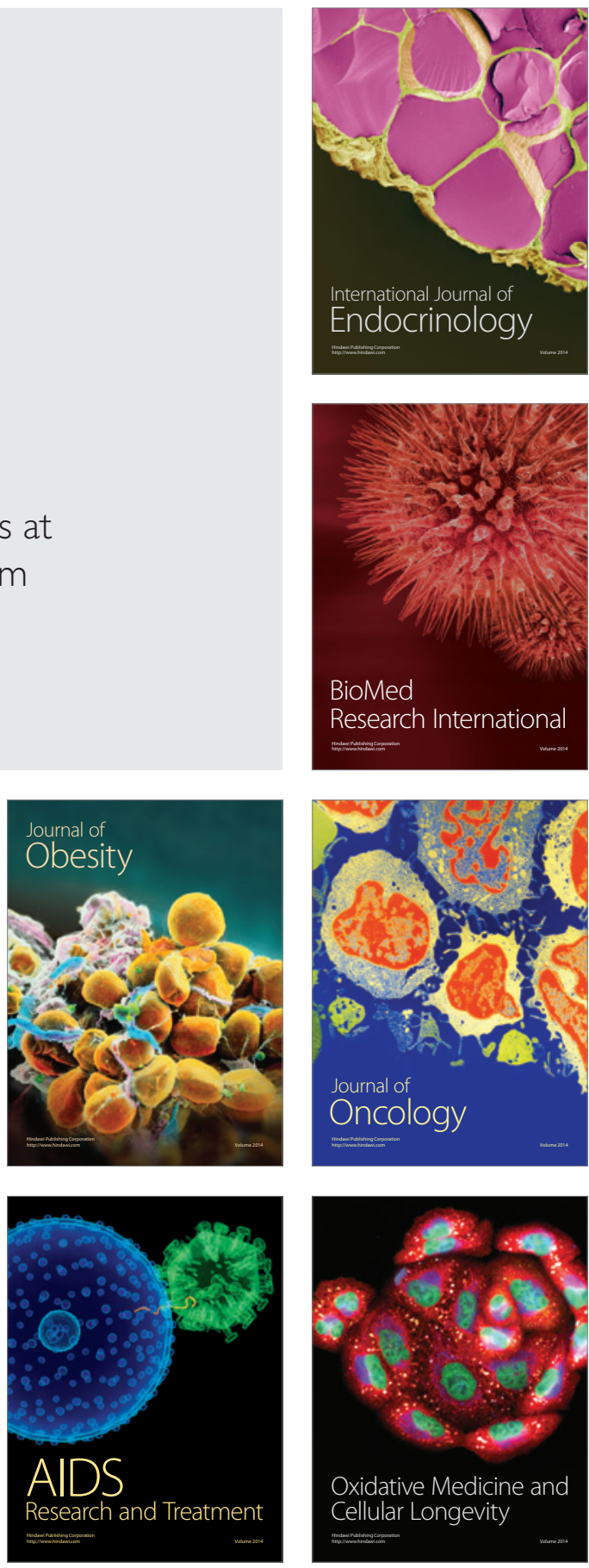